\title{
Actualidad del pensamiento de Augusto Del Noce
}

\section{Ricardo Delbosco*}

Pontificia Universidad Católica Argentina ricardodelbosco@yahoo.com.ar
Revista Cultura Económica

Año XXXIX $\bullet \mathrm{N}^{\circ} 102$

Diciembre 2021: 13-27

https://doi.org/10.46553/cecon.39.102.2021.p13-27

Resumen: Al enfocar el tema de la actualidad del pensamiento de Augusto Del Noce nos encontramos con dos cuestiones distintas, aunque relacionadas: el contenido de su pensamiento y su método. En el presente trabajo abordaremos ambas perspectivas. Con respecto a la primera mostraremos que aunque aparentemente Del Noce habla solo de temas que parecen superados, como el marxismo y el fascismo, en realidad revela pistas para comprender los problemas actuales y sus conexiones con la crisis del marxismo, la secularización y el nihilismo. Con respecto a la segunda cuestión, la referida al método, vincularemos la actualidad de Del Noce a un fundamento más profundo aún. Muchos de los estudiosos consideran a Del Noce un "filósofo a través de la historia", alguien que en medio de la cambiante realidad histórica supo siempre encontrar la "necesidad de las esencias filosóficas". En este sentido, sostendremos que su método, por estar fundado en una filosofía del ser, será siempre actual y replicable en cada nueva situación histórica.

Palabras clave: Del Noce; Marxismo; Secularización; Nihilismo; Metafísica

\section{Actuality of Augusto Del Noce's thought}

\begin{abstract}
In assessing to which extent Augusto Del Noce's thought remains relevant for examining current issues, we find two different yet related dimensions: the content of his though and his method. In this paper we will explore both of them. Regarding the former, we will show that although apparently Del Noce only addresses issues that seem to have been overcome, such as Marxism and Fascism, in reality his thought reveals clues about current problems and their connections with the crisis of Marxism and secularization. Regarding his method, we claim that the current relevance of Del Noce is related to an even deeper foundation. Many scholars consider Del Noce a "philosopher through history", someone who in the midst of changing historical reality is able to trace "philosophical essences". In this sense, we will argue that his method, being based on a philosophy of being, will always be relevant and replicable in each new historical situation.
\end{abstract}

Keywords: Del Noce; Marxism; Secularization; Nihilism; Metaphysics

* Recibido: 31/08/2021 - Aprobado: 02/11/2021 


\section{I. ¿Es Del Noce un filósofo actual?}

Cuestionarse sobre la actualidad de un autor es lo mismo que preguntarse si vale la pena estudiarlo. Si un pensador no tiene nada que decirnos hoy, no tiene sentido leerlo. Evidentemente, si dedicamos este trabajo a Del Noce se adivinará que responderemos afirmativamente a la pregunta sobre su actualidad. Tendremos que aclarar, sin embargo, en qué sentido hablamos de actualidad cuando nos referimos a un autor como Del Noce, quien si bien fue uno de los más importantes filósofos italianos del siglo XX, dedicó su vida a estudiar temas que hoy parecen superados. Tanto el marxismo como el fascismo podrían presentarse más como cuestiones de interés histórico que de actualidad filosófica. ¿Puede ser actual un autor que, desde una filosofía cristiana, abierta a la trascendencia, dedicó su obra más importante al estudio del ateísmo, en conexión con las expresiones culturales y políticas del siglo pasado?

Para comenzar a responder a este interrogante recurrimos al mismo Del Noce, quien en reiteradas ocasiones subraya la relación entre metafísica e historia, lo eterno y lo temporal. Para nuestro autor, las verdades eternas son inagotables y van desplegando sus virtualidades en la historia. Por eso, cuando un autor reflexiona sobre su tiempo se termina encontrando nuevamente con lo eterno, pero desde la particularidad que le toca vivir. En el esfuerzo que cada filósofo hace para responder a los problemas que se le presentan en su determinada época histórica, se revelan verdades que estaban contenidas virtualmente en los grandes filósofos del pasado. Del Noce se refiere, por ejemplo, a Santo Tomás y a Rosmini como los más grandes filósofos del pensamiento cristiano. Pues bien, todo lo verdadero y todo lo actual que hay en ellos se descubre, para el filósofo turinés, solo a través de ese trabajo personal, encarnado en la propia actualidad histórica, del que hablábamos, ya que "es inútil pensar que se pueda lograr descubrirlo a través de una pura deducción analítica a partir de lo que ellos escribieron, y son justamente ellos los que nos prohíben proceder de este modo"1 (Del Noce, 1994: 63). Es decir que, para nuestro autor, la actualidad de los autores del pasado, de aquellos que tienen realmente algo que sigue siendo vigente, no significa jamás que podamos repetir hoy sus ideas así como han quedado plasmadas en sus escritos, o sacar conclusiones con una mera deducción analítica. Y son estos mismos autores (obviamente la lista podría incluir gran cantidad de nombres) los que nos prohíben tomar esta actitud. Los grandes autores nos dejan, por decir así, un enorme capital de ideas y verdades, pero al mismo tiempo nos señalan con su ejemplo que a este tesoro solo se puede 
acceder con una búsqueda personal. Las verdades vistas por otros no pueden ser verdades para una persona hasta que no sean vistas por ella misma. No basta con leerlas o repetirlas. Las experiencias ajenas pueden orientarnos, pero solo nosotros podemos andar nuestro camino.

La actualidad de Del Noce tiene que ver con estos dos aspectos, el de las verdades que vio y el del camino que anduvo para llegar a verlas. Para hacer justicia a su legado no deberíamos limitarnos a proponer sus libros como respuesta a los problemas de hoy. Él mismo nos prohibiría que procediéramos de esta manera. Frente a su obra somos invitados a pensar para apropiarnos de las verdades que en ella aparecen a la luz de los nuevos problemas. Sus libros pueden seguir hablándole a los lectores de hoy porque contienen, detrás de los aspectos caducos, elementos imperecederos que, paradójicamente, solo se manifiestan a quien asume la responsabilidad de responder a los desafíos de su propio tiempo.

Dicho esto, que vale para cualquier autor que de alguna manera trascienda su tiempo, podemos intentar ahora enumerar algunas dificultades que surgen al hablar en particular de la actualidad de Del Noce.

En primer lugar, lo mismo que hace de Del Noce un filósofo único, el ser "filósofo a través de la historia" 2 , parece atentar contra la afirmación de su actualidad. Un autor en cuyo pensamiento son tan importantes los hechos históricos en los que se encuentra involucrado, parece estar condenado a limitar su vigencia a un determinado tiempo. ¿Cómo seguir leyendo hoy a alguien que habla permanentemente del fascismo, del marxismo, de las revueltas estudiantiles de los '6o, del cattocomunismo? El lenguaje y los temas delnocianos parecen estar demasiado marcados por una época que ya terminó. Incluso muchos de quienes comparten sus convicciones últimas creen que hoy los adversarios que debe enfrentar una filosofía cristiana son otros.

En segundo lugar, se añade el hecho de que nuestro autor se especializó en evitar los lugares comunes de los ambientes filosóficos italianos de su tiempo, con lo que llegó a hacer afirmaciones de las que no solo hoy es difícil ver su actualidad, sino también en el momento mismo en que eran pronunciadas por primera vez frente a sus coetáneos. Dedicar tantos estudios a Gentile, por ejemplo, es algo que parece propio solamente de la filosofía de la primera mitad del siglo XX. 
Por último, contra la afirmación de la actualidad delnociana, se alzan también las voces de los que, reconociéndole sus condiciones de profeta, de visionario, limitan sin embargo el alcance de su filosofía a la previsión de un acontecimiento, el de la caída del comunismo. Una vez cumplido lo que él había predicho, ya no quedan razones para seguir estudiándolo.

Firmes en nuestra convicción de que Del Noce es un autor actual, responderemos una a una a estas objeciones, que en buena medida se relacionan entre sí.

\section{Nuevos adversarios}

No caben dudas de que la situación actual no es la misma que la que tenía ante sus ojos Del Noce entre los años '50 y '80, en los que escribió la mayoría de sus libros. Hubo grandes cambios en el mundo no solo en el último tramo de su vida sino también en los más de treinta años que nos separan hoy de su muerte. Esto es observado, por ejemplo, por Vittorio Possenti:

Tal como se mencionó, la elaboración filosófica y los diagnósticos histórico-políticos de Del Noce parecen haberse asentado aproximadamente 30 años atrás, o quizás antes. Respecto a ese entonces, la condición espiritual de la época se presenta significativamente cambiada en encrucijadas relevantes: el ateísmo, especialmente el político, está en decadencia, y no emite señales de esperanza, aunque quedan un ateísmo científico, uno psicoanalítico, uno libertino, todos, sin embargo unidos bajo el signo - de por sí indicativo- del predominio de las formas negativodisolutivas sobre las positivas; el marxismo colapsó; el antiguo compromiso cristiano-burgués se ha roto (Possenti, 1995: 113-114).

Para responder a quien niega o relativiza la actualidad del filósofo turinés a partir de la constatación del evidente cambio en la actualidad histórica tenemos que seguir dos argumentaciones. La primera tendrá por objetivo mostrar que en la crítica delnociana a los adversarios del pasado hay elementos imperecederos, que pueden ser utilizados hoy para comprender y criticar a los nuevos fenómenos culturales que se nos presentan. La segunda apuntará a poner de manifiesto el hecho de que los nuevos adversarios que se enfrentan hoy a una filosofía de la trascendencia fueron vistos, o pre-vistos por Del Noce en sus últimos años, y que de alguna manera, ciertamente incompleta, fueron también objeto de su crítica. Si esto es así, entonces no se podría hablar de una especie de cierre del diagnóstico delnociano en los años 
de Il problema dell'ateismo, como si su análisis de la historia se hubiese frenado allí.

Veamos pues la primera. ¿Qué tipo de crítica hace Del Noce del comunismo y del fascismo? ¿Es solo una crítica histórica, política o también filosófica? La visión "transpolítica" de la historia que practica nuestro autor consiste justamente en elevarse a las causas filosóficas de estos movimientos políticos. Del Noce penetra hasta el origen mismo de estas ideologías identificando su parentesco profundo en el rechazo del conocimiento como intuición, como contemplación de algo dado. Comunismo y fascismo son dos expresiones de la filosofía de la praxis. Presuponen ambos una metafísica del devenir. Todas las críticas de nuestro autor a estos movimientos tienen en esta intuición de fondo, metafísica, su justificación última. La lectura filosófica de la historia contemporánea realizada por Del Noce presupone una metafísica del ser. No es posible considerar su pensamiento histórico-crítico sin tener en cuenta el alcance metafísico de sus argumentaciones. No se ha comprendido a Del Noce si se piensa que su crítica al comunismo se limita a una cuestión política, destinada a caducar. La crítica delnociana al fascismo y al comunismo es parte de una más profunda afirmación de la metafísica del ser y una demostración de la contradictoriedad de la filosofía del devenir. Desde este punto de vista, la lección delnociana sigue siendo vigente en la medida en que lo es también este tipo de metafísica, y en tanto y en cuanto los adversarios de esta sigan siendo expresiones de la filosofía del devenir. La lógica de la negación, propia de estos movimientos criticados por el filósofo turinés, es la misma lógica de los nuevos adversarios. La "heterogénesis de los fines”, expresión tan usada por Del Noce para expresar las contradicciones a las que lleva una filosofía del devenir cuando "se hace mundo", se explica por razones metafísicas, por lo que también se verificará una "heterogénesis de los fines” en las nuevas formas de negación de la metafísica del ser.

Para introducirnos en la segunda argumentación a favor de la actualidad de Del Noce, a pesar del cambio de época, necesitamos primero saber cuáles son los nuevos adversarios que, según algunos críticos, vienen después de los diagnósticos delnocianos. Vittorio Possenti, quien, a nuestro entender, oscila entre un intento de partir de los aportes de Del Noce para ir luego más allá, y una crítica de los límites del diagnóstico delnociano, propone lo siguiente:

Si nos dirigimos hacia la actualidad histórica, aquí el marxismo, el actualismo, el totalitarismo político, que representaron los máximos "contra" de Del Noce, aparecen agotados, mientras que 
emergen como nuevos adversarios de los "valores tradicionales" el materialismo burgués, el neoiluminismo de base empirista, la ideología de la sociedad tecnocrática (Possenti, 1995: 61).

El mismo Francesco Mercadante, quien ciertamente no es crítico respecto de Del Noce, parece compartir esta interpretación según la cual nuestro autor no hablaría de los nuevos adversarios de la filosofía de la trascendencia. En el contexto, es justo aclararlo, de un análisis más político que metafísico, deja escapar esta afirmación:

¿Y después del suicidio? En los escritos de Augusto Del Noce no está la respuesta a esta pregunta. Él nos acompaña hasta el fin del comunismo (Mercadante, 1992: 39).

Mercadante no estaría con esto descartando la posibilidad de que los principios últimos de la crítica delnociana sirvieran para enfrentar las posturas inmanentistas de hoy, pero se trataría de algo a lo que nuestro autor no habría hecho ninguna alusión.

Siguiendo los textos de Del Noce podemos encontrar, en cambio, numerosas citas en las que éste se refiere a los mismos adversarios que Possenti enumera como los principales en el presente. Ya en 1970, por ejemplo, definía así a la sociedad tecnológica postmarxista:

[...] es una sociedad que acepta todas las negaciones del marxismo en cuanto al pensamiento contemplativo, la religión y la metafísica; que, por tanto, acepta la reducción marxista de las ideas a un instrumento de producción; pero que, por otro lado, rechaza los aspectos revolucionarios-mesiánicos del marxismo, es decir, lo que permanece de religioso en la idea revolucionaria. En este sentido, representa verdaderamente el espíritu burgués en su estado puro; el espíritu burgués que ha triunfado sobre sus dos adversarios tradicionales, la religión trascendente y el pensamiento revolucionario (Del Noce, 1970: 14).

¿No parece entonces que la mutación advertida por Possenti ya había sido diagnosticada por Del Noce? Se puede decir que nuestro autor pasa de la consideración del actualismo y del marxismo como principales "contra" a la de la sociedad opulenta, que ya en 1970 se le presenta como una realidad preocupante. Quizás pueda desorientar el hecho de que para Del Noce el marxismo siga siendo, aunque ya en estado de descomposición, el sujeto de la historia contemporánea. Pero en realidad nuestro autor nos muestra que la 
misma sociedad opulenta y tecnológica, el mismo occidentalismo burgués triunfante, no son más que el resultado del suicidio de la revolución:

[...] la historia de nuestro siglo es la del éxito total del marxismo en el sentido de que realmente cambió el mundo, según la famosa undécima tesis sobre Feuerbach, y no solo la parte del mundo donde triunfó el comunismo; sin embargo, este completo éxito coincide con su completo fracaso, en el sentido de que tanto las posiciones ideales como las prácticas del pensamiento racionalista-laicista posterior son aspectos de su descomposición (Del Noce, 1989: 139).

El último Del Noce sigue convencido de que la comprensión del marxismo es fundamental para entender la sociedad capitalista posterior a la caída del comunismo. Esta convicción, lejos de ser una reconstrucción $a$ posteriori de sus análisis, es verdaderamente temprana en nuestro autor. En 1963 escribe su ensayo "Appunti sull'irreligione occidentale", que después será parte de Il problema dell'ateismo, en el que sostiene que:

De hecho, la sociedad opulenta es la única en la historia del mundo que no se origina en una religión, sino que surge esencialmente contra una religión, aunque, paradójicamente, esta religión es la marxista; y aunque por causa del adversario común se valga de la concurrencia de fuerzas religiosas (Del Noce, 1964: 318-319).

Como vemos, la sociedad opulenta se le presentaba, por su subordinación en la oposición, "no como extraña al marxismo, sino como su destino, como una extensión extrema de su momento materialista" (Del Noce, 1981: 321). Lo suyo con el marxismo no es una obsesión, o un estancamiento en el tiempo. A través de la crítica del marxismo accede a una comprensión filosófica de la historia contemporánea, que se presenta como el cumplimiento y el fracaso de esta ideología. Si la constante referencia al marxismo fuera un signo de la miopía de nuestro autor frente a los nuevos adversarios de la filosofía cristiana que él quería defender, entonces no se explicaría aquella frase de la que Domenico Settembrini es testigo:

Durante el debate que se encendió sobre este tema, Del Noce supo asombrarme profundamente al declarar más o menos textualmente: "Ustedes saben cuánto odio al comunismo: pues bien, si la única alternativa válida a este -cosa que no creo- tuviera que ser la sociedad de consumo, yo elegiría el comunismo" (Settembrini, 1995: 156). 
Evidentemente Del Noce no piensa en el marxismo como único adversario, ni siquiera como el más peligroso. La sociedad consumista, opulenta, se le presenta como algo más corrosivo aún. Sin embargo, el marxismo sigue siendo la clave para entender este proceso.

\section{Del Noce y el nihilismo posmoderno}

Con lo dicho no resultará difícil dar el siguiente paso. Augusto Del Noce, autor del fin de la modernidad filosófica, al menos si la entendemos en sentido axiológico, profeta y testigo del fracaso del racionalismo moderno, cintuyó el advenimiento de la era filosófica posmoderna? Más allá de la crítica a la sociedad opulenta que se afirmaba con la caída del comunismo, ¿previó la llegada del nihilismo filosófico, el cumplimiento de la profecía de Nietzsche?

Giuseppe Riconda no tiene dudas en responder afirmativamente a estos interrogantes:

El hecho de que Del Noce hable mucho de la modernidad no debe llevarnos a pensar que él no tenga en cuenta el problema de la posmodernidad. Lo posmoderno es, en su visión, la radicalización última y la intensificación máxima de la línea secularista de la modernidad: se inscribe en el segundo de los dos momentos de secularización mencionados anteriormente. Si la modernidad en este aspecto tiene en su centro la idea de revolución, la era posmoderna es la resultante de lo que hemos visto como su fracaso (Riconda, 2007: 25).

Los dos momentos de la secularización a los que se refiere Riconda son el de las religiones seculares, como el fascismo y el comunismo, sobre todo antes del final de la segunda guerra, y el de la irreligión occidental que caracteriza al mundo occidental de la posguerra. En la primera etapa tenemos distintos intentos de apropiación de los contenidos religiosos en un contexto inmanentista, en la segunda nos encontramos frente a la negación radical de todo tipo de religiosidad, incluso la inmanentista. Entre estas dos etapas hay un nexo profundo. Lo que permanece detrás de este cambio es el momento negativo de la filosofía de Marx, presente tanto en el comunismo como en el fascismo (a través de Gentile). Es así que, siempre a partir de la comprensión de la dinámica interna del marxismo, Del Noce es capaz de ver el comienzo del nihilismo posmoderno. Alguno podría preguntarse cuál es la relación entre Marx, cuya revolución apunta a la construcción de un futuro distinto, el de la sociedad sin clases, y el nihilismo, en el que no hay lugar para ningún tipo de esperanza. Del Noce sostiene que se trata de un claro ejemplo de 
"heterogénesis de los fines". Marx no hubiera imaginado este resultado para su filosofía de la praxis, pero el momento negativo contenido en ella será la clave del nihilismo futuro:

Pensemos en cambio en el término nihilismo que se utiliza hoy en día en el sentido de la caída en el mundo occidental de los valores hasta ahora considerados supremos. Hay que decir que Marx de ninguna manera había previsto el surgimiento de esta actitud [...] el nihilismo de la sociedad occidental no puede explicarse sin referirse a este contragolpe del marxismo. Quizás no fue solo la cultura marxista la que lo promovió, pero la función que desempeñó en este fenómeno fue primordial y determinante (Del Noce, 1989: 152).

En la intuición delnociana de las causas de la disolución del marxismo estaba contenida ya la previsión del nihilismo posmoderno. El suicidio de la revolución era el nacimiento de la posmodernidad. La actualidad de Del Noce en este punto es superlativa. En él tenemos a un filósofo que desde la metafísica del ser criticó ante factum los efectos de la filosofía del devenir. Su lección nos permite evitar la búsqueda de falsas soluciones al problema del nihilismo, como aquellas que lo ven como una oportunidad para un nuevo punto de partida, o como la condición necesaria para construir una nueva realidad, sin ataduras con el pasado. La reconstrucción delnociana de la historia de la esencia filosófica que desemboca en el nihilismo es prueba suficiente de que estamos ante una conclusión, y no ante el comienzo de algo nuevo:

Pero ahora, ¿qué otra cosa es el nihilismo sino una actitud resultante de la mutua exclusión de dos actitudes en absoluta antítesis (precisamente el milenarismo, como confianza en el nuevo eón, y el negativismo) que, sin embargo, se presentan igualmente impuestas por la historia? De ahí surge una consecuencia muy importante: que el nihilismo no puede entenderse en absoluto como un vacío a la espera de que algo lo llene; ni como fase de transición, porque en cambio es una conclusión (Del Noce \& Spirito, 1971: 208).

Frente al nihilismo la única actitud posible es la misma que Del Noce proponía ante la concepción axiológica de la modernidad: "Utilizo términos similares a los de Toynbee, 'respuesta al desafío', en contraposición a los de [inveramento] 'realización' y 'superación”' (Del Noce, 1994: 33). Del nihilismo no hay nada que pueda ser objeto de inveramento. Representa el final de una línea que no puede ser continuada o superada. La metafísica del 
ser debe asumir el desafío de esta nueva tendencia para dar una respuesta, y no para integrarla o encontrar en ella un núcleo de verdad. Del Noce no hizo más, ni menos, que poner de manifiesto el mecanismo filosófico profundo que llevó a estos resultados, dejando a disposición de sus sucesores herramientas de un valor inapreciable. La vida no le permitió avanzar mucho en la respuesta a este nuevo desafío. Pero no sería justo decir que su reflexión se detuvo en el fin del marxismo, cuando entre sus escritos podemos descubrir textos como el que sigue:

\begin{abstract}
Parece que el proceso hacia el futuro es el del éxito de una cultura fisicalista-científico-tecnológica, a la cual corresponde una moral que invierte el imperativo kantiano y por tanto suena: "considera la humanidad en ti y en los demás como un medio y no como un fin"; también en ti, porque el así llamado autorrealizarte, según la fórmula actual, está subordinado a tu convertirte en medio. "Lo que estoy contando es la historia de los próximos dos siglos. Describo lo que vendrá: el advenimiento del nihilismo". Así decía Nietzsche en uno de sus últimos fragmentos. Y quizás la inversión del imperativo kantiano esté entre las posibles definiciones de lo que hoy se llama nihilismo (Del Noce, 1983: 73).
\end{abstract}

La mención de Nietzsche no debe engañarnos. Del Noce no entiende el nihilismo solamente al modo en que fue anticipado por este autor un siglo atrás. Ya en 1984 veía la característica distintiva del nuevo nihilismo posmoderno. "El nihilismo ya no es hoy el nihilismo trágico de Nietzsche o, en parte, de Dostoevskij, es un nihilismo 'aceptado', por así decir” (Borghesi \& Brunelli, 1984: 356). Ese mismo año, en una carta a Rodolfo Quadrelli, dice que "el nihilismo hoy corriente es el nihilismo alegre [gaio]", porque, como aclara más adelante, "no tiene inquietudes (quizás incluso podría definirse como la supresión del 'inquietum cor meum' agustiniano)”3 (Rondoni, 1994: 10). El diagnóstico delnociano no podría ser más preciso: el pasaje del nihilismo trágico al nihilismo "alegre" como definición de nuestra época.

La sociedad tecnológica, opulenta, utilitarista y el nihilismo posmoderno, como puede verse, están presentes como interlocutores polémicos en la meditación delnociana, y son vistos a la luz de su matriz filosófico-metafísica, la de la filosofía del devenir que después de Marx se afirma como una filosofía de la praxis.

\title{
IV. El carácter profético del pensamiento delnociano
}


Cuando murió Augusto Del Noce en diciembre de 1989, lo único en lo que estuvieron de acuerdo todos los que dedicaron a él una reflexión en la prensa fue en calificar su obra como profética4. La necesidad de simplificar y resumir la vida y el pensamiento de un autor en pocas líneas llevó a la presentación de Del Noce como el autor que previó el fin del comunismo. Por otra parte, la coincidencia de su muerte con la reciente caída del muro de Berlín representaba una tentación irresistible para proceder de esta manera. No es equivocado hablar de un cierto carácter profético de la filosofía de nuestro autor, pero es necesario aclarar el sentido en que usamos esta expresión. Danilo Castellano, comentando esto, dice:

De hecho, se ha subrayado universalmente el carácter "profético" del pensamiento de Augusto Del Noce sobre el "suicidio de la revolución", es decir, sobre las contradicciones del régimen marxista que, según él, no podían dejar de llevar (como de hecho lo hicieron) al colapso de los sistemas políticos basados en una ideología que predicaba "una autoliberación de la humanidad a lo largo de la historia" (Del Noce, 1978: 5-6). Esto es correcto. Pero se vuelve unilateral y, por tanto, erróneo si nos detenemos únicamente en el aspecto "profético". Del Noce, de hecho, teorizó el suicidio de la revolución sobre la base de un "pensamiento positivo". Y esto, con motivo de su muerte, la casi generalidad de la prensa pareció ignorarlo. De su crítica al marxismo parecía subrayar lo que el propio Del Noce consideraba un error: la lucha contra el marxismo no en su aspecto de ateísmo, sino en su aspecto de religión (Del Noce, 1965: CCVIII). (Castellano, 1992: 14).

Es decir que si lo definimos como "profético" simplemente porque anticipó un acontecimiento como el fin del comunismo denunciando las contradicciones que había en este régimen, estaremos dejando escapar lo más importante del pensamiento de este filósofo, su propuesta positiva. Esta caracterización de Del Noce puede llegar a ser, según Castellano, una estrategia perfecta para encubrir, detrás de un aparente elogio, el certificado de defunción de la filosofía delnociana. El valor de su obra se limitaría a la previsión de un hecho hoy ya consumado, y por lo tanto dejaría de tener sentido estudiarlo en el presente. Ya tuvimos ocasión de mostrar que para nosotros esto no es así, que su reflexión trasciende este hecho histórico, y que sus intuiciones siguen siendo vigentes porque se mueven en un nivel metafísico. Ahora debemos tratar de entender en qué sentido se puede decir efectivamente que la filosofía de Del Noce es profética, sin caer en este empobrecimiento de su figura. 
Vittorio Mathieu aporta interesantes observaciones respecto de esta cuestión:

Había en Del Noce un tipo particular de sensibilidad hacia los acontecimientos. Y es lo que explica el carácter a veces casi profético de algunas de sus declaraciones, que no son proféticas en el sentido de que se refieren al futuro, ni en el sentido de que quieren presentarse como el anuncio de una verdad trascendente. Son proféticas solo en el sentido de que interpretan el presente de manera reveladora (Mathieu, 1995: 36).

Aquí nos acercamos al verdadero sentido del carácter profético de este autor. Claramente no se trata de un fenómeno sobrenatural, religioso, y en este sentido Mathieu descarta que se pueda hablar aquí de profecía como anuncio de una verdad trascendente. Del Noce interpreta el presente en un modo revelador. ¿Qué es lo que revela, lo que pone de manifiesto con su mirada sobre los eventos históricos? Seguramente las esencias filosóficas, la causalidad ideal de estos eventos. Es profético porque lee en lo profundo y lo saca a la luz. En un siglo como el que le tocó vivir, además, tiene una ventaja. La filosofía se ha hecho mundo, los grandes acontecimientos estuvieron marcados por sistemas filosóficos, y por eso se hace más clara la racionalidad de la historia.

Ahora bien, si las esencias filosóficas tienen una cierta vida propia, si las opciones iniciales en filosofía llevan necesariamente a determinadas consecuencias, tal como lo entiende Del Noce, entonces el carácter revelador de un pensamiento que es capaz de identificar estas esencias filosóficas se proyecta de alguna manera también hacia el futuro. Éste es el aspecto que, superficialmente, fue visto por muchos en la filosofía de Del Noce. Menos visto en cambio fue el hecho de que esta capacidad de "previsión" se basaba en una filosofía del ser cuya fuerza de argumentación era la misma fuerza del orden de lo real. No se trata de adivinar ni de ver sobrenaturalmente el futuro, sino de comprender las exigencias del orden de lo real, del orden del ser. Desde esta perspectiva se ve con claridad lo que tiene sentido y lo que no, lo que está destinado a crecer, y lo que perecerá como consecuencia de sus contradicciones internas.

\section{La "vía negativa" y la interpretación "transpolítica" de la historia}


Para concluir nuestra mirada acerca de la vigencia de Del Noce, haremos un breve análisis de dos aspectos adicionales de su método. En primer lugar, la opción que hace nuestro autor por la "vía negativa", es decir, el hecho de que Del Noce en sus obras se dedica más a desarrollar las contradicciones del inmanentismo que a enunciar positivamente los principios de la filosofía del ser. En segundo lugar, diremos algo sobre la "interpretación transpolítica" de la historia, expresión que ya hemos explicado. ¿Tiene sentido seguir utilizando hoy la metodología de la vía negativa? ¿Es aplicable la interpretación transpolítica a la realidad actual?

Respecto de la vía negativa, la respuesta parece no ser tan complicada. La validez del principio de no contradicción no está en juego. Lo único que se puede poner en duda es si en la situación actual sigue prevaleciendo una filosofía que lo niega, como ocurría el siglo pasado. Del Noce justificaba su método por el hecho de que se multiplicaban los sistemas e ideologías que negaban la validez de este principio. La mejor forma de mostrar la verdad parecía ser la de poner de manifiesto las contradicciones de estas posturas. No era ese el tiempo de limitarse a enunciar positivamente la verdad de la metafísica del ser. Su verdad cobraría mayor luz en la demostración de la falsedad de la filosofía que se le oponía. ¿La situación de hoy es distinta? Probablemente no. No parece exagerado hablar hoy de un generalizado olvido o negación de la metafísica del ser. Podemos decir entonces que la vía negativa elegida por el filósofo piamontés para mostrar por contraste la verdad de la metafísica realista sigue siendo válida y adecuada a los tiempos que corren. No hace falta que digamos que es el único camino, ni el mejor. Distintos modos de presentación y defensa de la metafísica pueden complementarse. Nos basta saber que su método sigue vigente en este aspecto.

Pasemos entonces a la interpretación transpolítica. Aquí las cosas parecen complicarse un poco más. En el siglo XXI no tenemos, al menos no a un nivel tan determinante, fenómenos como el comunismo o el fascismo. Si la del siglo XX fue una historia particularmente filosófica, ¿se puede decir lo mismo de la del comienzo de este siglo? ¿Significa esto que la interpretación transpolítica ya no tiene sentido? Dejamos abierta la cuestión sobre la mayor o menor influencia de la filosofía en este siglo respecto del pasado. Aun cuando se tratara de un período "menos filosófico", en el sentido delnociano, siempre se podría seguir indagando sobre los presupuestos metafísicos últimos de las corrientes filosóficas y de los movimientos políticos y culturales de la actualidad. La interpretación transpolítica tiene una vigencia 
imperecedera porque detrás de cualquier manifestación cultural, política e histórica hay siempre opciones con implicancias filosóficas, hay siempre presupuesta una concepción de lo real, una metafísica. El método delnociano consiste en indagar en lo profundo de los hechos, movimientos, ideologías, etc., para descubrir sus presupuestos últimos. Este modo de proceder será siempre vigente. Declararlo superado es lo mismo que declarar superada la filosofía.

\section{Referencias Bibliográficas}

Borghesi, M., \& Brunelli, L. (1984). "Storia di un pensatore solitario, intervista con A. Del Noce”. En Mina, A. (Ed.) (2007). Verità $e$ ragione nella storia. Antologia di scritti. Milán: BUR.

Castellano, D. (1992). "Introduzione. Augusto Del Noce, un filosofo attraverso la storia”. En Castellano, D. (Ed.). Augusto Del Noce. Il pensiero filosófico. Napoli: Edizioni Scientifiche Italiane.

Del Noce, A. (1964). Il problema dell'ateismo. Bolonia: Il Mulino.

Del Noce, A. (1970). L'epoca della secolarizzazione. Milán: Ed. Giuffré.

Del Noce, A. (1981). Il cattolico comunista. Milán: Rusconi.

Del Noce, A. (1983). "Note sulla secolarizzazione e il pensiero religioso". Il Nuovo Areopago, 2(3), 66-79.

Del Noce, A. (1989). "Secolarizzazione e crisi della modernità". En Mina, A.

(Ed.) (2007). Verità e ragione nella storia. Antologia di scritti. Milán: BUR.

Del Noce, A. (1994). I cattolici e il progresismo. Milán: Ed. Leonardo.

Del Noce, A., \& Spirito, U. (1971). Tramonto o eclissi dei valori tradizionali? Milán: Rusconi.

Mathieu, V. (1995). "Filosofia e storia della filosofia in A. Del Noce”. En Rizza, A. (Ed.). Augusto Del Noce. Il problema della modernità. Roma: Studium.

Mercadante, F. (1992). "L'interpretazione filosofica della storia contemporanea e l'eresia italiana in Augusto Del Noce". En Castellano, D. (Ed.). Augusto Del Noce. Il pensiero filosófico. Nápoles: Edizioni Scientifiche Italiane.

Possenti, V. (1995). Cattolicesimo e modernità. Balbo, Del Noce, Rodano. Milán: Ed. Ares.

Riconda, G. (2007). "Prefazione". En Del Noce, A. Modernità. Interpretazione transpolitica della storia contemporánea. Brescia: Morcelliana.

Rondoni, D. (1994). "Il nulla gaio". En Il Sabato, 02.1994, n. 2, 10.

Settembrini, D. (1995). "Borghesia, liberalismo e fascismo". En Rizza, A. (Ed.). Augusto Del Noce. Il problema della modernità. Roma: Studium. 
${ }^{1}$ Todas las traducciones de los textos originales de Del Noce y sus comentadores son nuestras.

${ }^{2}$ Sobre este punto han coincidido muchos estudiosos del pensamiento de Del Noce, como por ejemplo Mathieu, V. (1995). "Filosofia e storia della filosofia in A. Del Noce". En Rizza, A. (ed.). Augusto Del Noce. Il problema della modernità. Roma: Studium, pp. 29-38.; Zovatto, P. (1995). "Il filosofare di Augusto Del Noce". En Mercadante, F., \& Lattanzi, V. (ed.) (2001). Essenze filosofiche e attualità storica, Atti del Convegno internazionale di studi su Augusto Del Noce. Roma, 9-11 novembre 1995. Roma: Ed. Spes-Fondazione Del Noce, p. 725. Livi, A. (2007). Storia sociale della filosofía. Roma: Società Editrice Dante Alighieri, p. 471.

3 Carta de Del Noce a Quadrelli (08.01.1984), publicada en Rondoni, D. (1994). "Il nulla gaio", en Il Sabato 02.1994, n. 2, 10.

4 Cfr. Buttiglione, R. (1990). "Il profeta del grande crollo", en Avvenire, 02.01.1990; Ronfani, V. (1990). "Antimarxista profetico", en L’Unità, 02.01.1990; Grisi, F. (1990). "Aveva previsto la fine del comunismo", en Il Borghese, 21.01.1990; Pinto, P. (1990). "Teorizzò il fallimento del marxismo", en Il Popolo, 02.01.1990; Fumo, N. (1990). “Aveva anticipato l'evoluzione della nostra storia", en Vita Nuova, 12.01.1990; Barbiellini Amidei, G. (1990). "Il filosofo che previde il suicidio della rivoluzione", en Il Tempo, 02.01.1990. 